\title{
PERSONAL CARE ROBOTS FOR SENIOR ADULTS - sciendo ANALYSIS AND ASSESSMENT OF THE CURRENT STATE OF SELECTED GERONTECHNOLOGY
}

doi:10.2478/mape-2018-0109

Date of submission of the article to the Editor: 03/2018

Date of acceptance of the article by the Editor: 06/2018

MAPE 2018, volume 1, issue 1, pp. 867-873

Dr hab. inż. Katarzyna Halicka

Bialystok University of Technology Poland

\begin{abstract}
As part of this article, research work aimed at acquiring new knowledge regarding the analysis and assessment of arbitrarily selected gerontechnology: personal care robots for older adults. The results planned to be achieved under the article have not been reflected in previous scientific studies. Until now, no research has been carried out to assess this technology regarding heterogeneous criteria. The existing research results only concern the study of the acceptability of the technologies used by older people to improve their quality of life. The opinions of prospective potential users were not considered as well as their age and place of posting or education. Neither were marketing, social and ethical aspects, competitiveness or innovation. The author will use the proprietary methodology of prospective technology analysis (PAT) to analyse and evaluate the technology. This methodology allows assessing the current state of technology. It enables providing knowledge on characteristic features of the technology, current and potential applications of a given technology and necessary for the development of analysed resource technologies, as well as the impact of technology on the environment and the environment on technology.
\end{abstract}

Keywords: technology assessment, prospective technology analysis gerontechnology, humanoid robots

\section{INTRODUCTION}

Over the last 27 years, Poland has seen a slowdown in demographic development and significant changes in the age structure of its inhabitants. In 1989-2016, the number of older people in Poland increased by over 2.9 million. The share of people over 60 in the general population increased by more than 7.50 percentage points, i.e. from $12.63 \%$ in 1989 to $20.22 \%$ in 2016. The ageing process of the population will influence the priorities and directions of social policy (Ejdys and Gedvilaite, 2017). One of the basic goals of social policy towards older people is to activate and counteract dependence. The use of new technologies may contribute to increasing independence and activation of older people. Currently, the response is emerging to the existing problem faced by older people, namely, the gerontechnology, which is the science of technology and ageing to improve the everyday life of older people (Graafmans et al., 1998). In the narrow sense, gerontechnology means technologies that facilitate access for older people to all goods, services and infrastructure (Bronswijk et al., 2009). The author has accepted the second definition for her research.

An interdisciplinary approach is important here, consistent with the concept of sustainable development and combining research with design, production and marketing. In the literature on the subject, the social aspect of gerontechnology related to the ageing process (ageincreasing physical and mental dysfunctions) was primarily taken up (Mostaghel and Oghazi, 2017). The technological aspect has been marginalised, despite the fact that one of the opinions of gerontechnology is planning research, designing and introducing technology to be used by the aging population (Görer et. al., 2017). To be able to market this type of technology, a detailed analysis and evaluation of the current state of these technologies are necessary. It is not enough to identify the desired and expected attributes that these technologies should have. It is also indispensable to identify the technology's priority features, considering criteria 
such as their functionality, usability, innovation, marketing, social and ethical aspects. This article analyses and assesses one of many gerontechnology topics - personal care robots for older adults.

\section{METHODOLOGY OF RESEARCH}

Technology analysis, due to the complexity and, above all, the pace of technological changes on the global market, is difficult (Cagnin et. al, 2008). The analysis of technology is closely related to the development of a technological strategy (Nazarko, 2017). The literature review indicates that the following methods are most often used to analyse technology in the context of its current state: the technology readiness level, technology S-curves, the Analytic Hierarchy Process, bibliometric, patent analysis, statistical analysis, survey, Delphi method (Haegeman et. al, 2017; Nazarko et. al, 2017; Radziszewski et. al, 2017). To analyse and assess the current state of technology: personal care robots for older adults, the original method of prospective technology analysis was used.

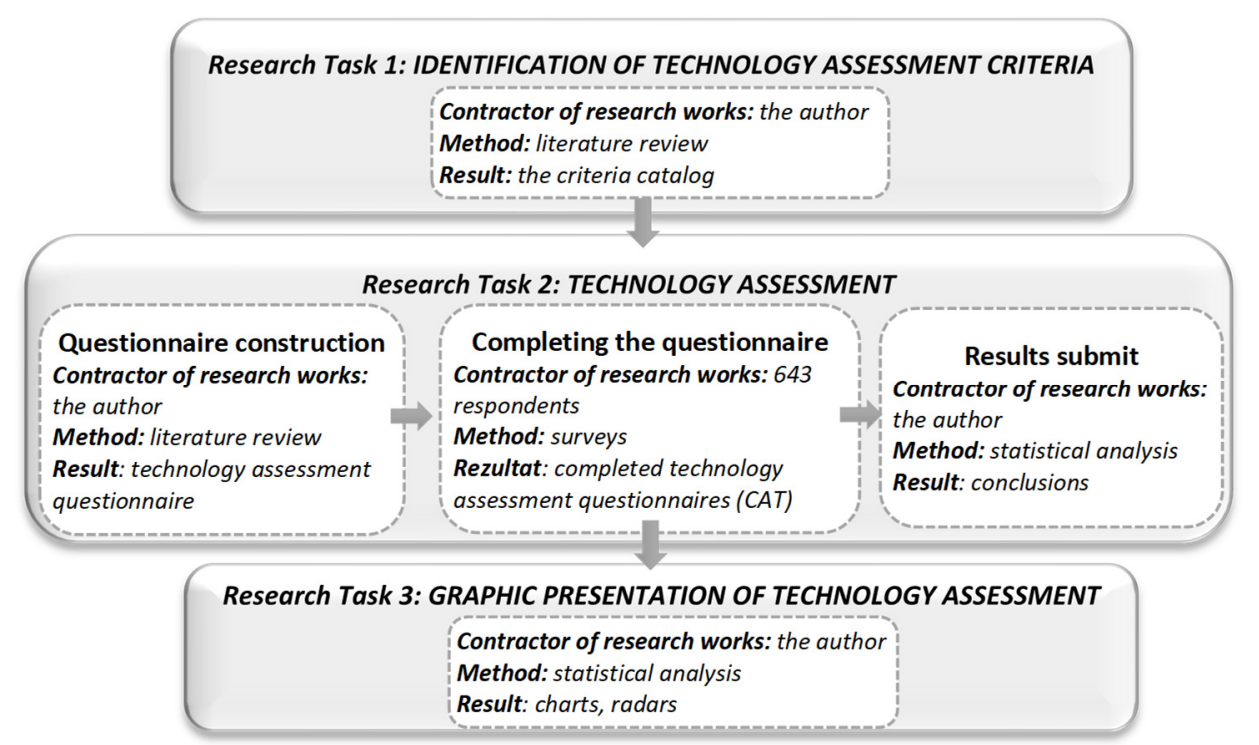

Fig. 1. Scheme depicting the operationalisation of analysis and assessment of personal care robots for older adults

According to the PAT methodology, the analysis of the current state of technology - called the phase of technology understanding - is awarded on the assessment in terms of its technological maturity and innovation (Ejdys, 2015). Social, ethical and ecological criteria have also been considered during the analysis and assessment (Halicka, 2016). As regards personal care robots for older adults, the processes of technology analysis and assessment were carried out in three consecutive stages (Figure 1). Three research tasks are presented in it in connection with individual research methods. Initially, within the first research sentence, based on the literature, the criteria for the assessment of technology regarding innovation, marketing, socio-ethics, usability and functionality were identified. In turn, as part of the second research task, the technology was evaluated considering the criteria selected in Task 1 . The last research task consisted in a graphic presentation of the technology assessment: personal care robots for older adults.

\section{IDENTIFICATION OF TECHNOLOGY ASSESSMENT CRITERIA}

Based on the literature review, five groups of technology assessment criteria were selected: regarding innovation, marketing aspects, socio-ethics, usability, and functionality. The criteria have been developed in the form of statements. The catalogue of criteria prepared by the author 
consisted of 27 statements. At the same time, seven concerned marketing aspects (M1-I M7), followed by five statements concerning technology innovation (11-15), socio-ethical aspects (SP1SP5), usability (U1-U5) and technology functionality (F1-F5). The list of criteria used to assess the technology of personal care robots for older adults is presented in Table 1.

Table 1

Catalogue of technology assessment criteria

\begin{tabular}{|c|c|}
\hline Acronym & The name of the criterion \\
\hline \multicolumn{2}{|r|}{ Innovation } \\
\hline 11 & Personal care robots for older adults is a very innovative solution that is in demand \\
\hline 12 & $\begin{array}{l}\text { Personal care robots for older adults will significantly improve the quality of the existing care } \\
\text { system }\end{array}$ \\
\hline 13 & Personal care robots for older adults is a breakthrough in the world \\
\hline 14 & Personal care robots for older adults is a breakthrough solution on the scale of Poland \\
\hline 15 & Personal care robots for older adults can significantly improve the living comfort of older people \\
\hline \multicolumn{2}{|r|}{ Marketing aspects } \\
\hline M1 & On the part of older people, there is a need for robots supporting care for the older people \\
\hline M2 & On the part of family members, there is a need for robots supporting care for the older people \\
\hline M3 & $\begin{array}{l}\text { On the part of institutions responsible for care for the older people(e.g. nursing homes), there is a } \\
\text { need for robots supporting care for the older people }\end{array}$ \\
\hline M4 & $\begin{array}{l}\text { The use of robots to care for the older people will be a source of additional benefits for their users } \\
\text { (24-hour attendance, 24-hour care, a sense of security), unavailable when using other solutions }\end{array}$ \\
\hline M5 & $\begin{array}{l}\text { The global demand for robot supporting care for the older people is associated with temporary } \\
\text { fashion }\end{array}$ \\
\hline M6 & Using a robot to care for an older people person will not require new, specialist knowledge \\
\hline M7 & The robot's appearance will have a significant impact on the scale of its use in everyday life \\
\hline \multicolumn{2}{|r|}{ Socio-ethical aspects } \\
\hline S1 & The widespread use of robots in the care of the older people will bring measurable social benefits \\
\hline S2 & The widespread use of robots in the care of the older people will create new jobs \\
\hline S3 & $\begin{array}{l}\text { The widespread use of robots in the care of the older people will bring measurable benefits to } \\
\text { human health and the quality of human life }\end{array}$ \\
\hline S4 & The widespread use of robots in the care of the older people can be a source of social problems \\
\hline S5 & $\begin{array}{l}\text { The widespread use of robots in the care of the older people can be the cause of moral dilemmas } \\
\text { and doubts as to whether you can entrust the robot with care for the older people }\end{array}$ \\
\hline \multicolumn{2}{|r|}{ Usability } \\
\hline U1 & The use of robots will improve the quality of care services for the older people \\
\hline U2 & The use of robots to care for the older people will improve the safety of the older people \\
\hline U3 & The use of robots will be of particular importance in the care of lonely people \\
\hline $\mathrm{U} 4$ & $\begin{array}{l}\text { The use of robots to care for the older people will contribute to spending the time of the older } \\
\text { people in a pleasant way }\end{array}$ \\
\hline U5 & I believe that being in the presence of a robot can be pleasant \\
\hline \multicolumn{2}{|r|}{ Functionality } \\
\hline F1 & The robot will be able to perform difficult activities (e.g. lifting people, help with movement) \\
\hline F2 & The robot will remind the older people about the necessity of taking medication \\
\hline F3 & The robot will be able to interact or communicate with the robot \\
\hline F4 & The robot will be able to inform the relatives about the health of the older people \\
\hline F5 & The robot will be able to call for assistance to an older people person \\
\hline
\end{tabular}

\section{TECHNOLOGY ASSESSMENT WITH DIFFERENT CRITERIA}

To assess the technology, questionnaire surveys were carried out. The research was carried out between March and April 2018 on a sample of 643 Poles. The respondents represented all voivodships of Poland. The electronic form of the survey was distributed using social media and snowball sampling. The respondents evaluated the assessment of the analysed technology using the 7-point Likert scale, where 1 - "it definitely means I strongly disagree with the given statement", 7 - "I strongly agree". Since not every respondent was familiar with the formulation of a humanoid robot, the term robot was used in the questionnaire. In the sample structure, $32.7 \%$ (210 people) were people aged 18-25, 24.9\% (160 people) people aged $26-40,25.8 \%$ (166 people) aged $41-60$ and $16.4 \%$ (107 people) over the age of 60 . 


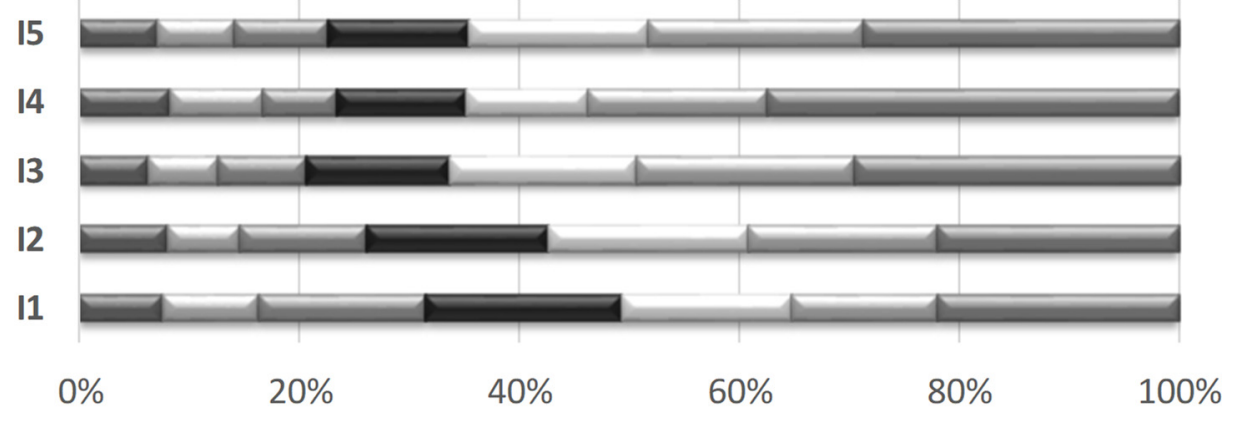

$\square 1$ - I strongly disagree $\square 2 \square 3 \square 4 \square 5 \square 6 \square 7$ - I strongly agree

Fig. 2. Technology assessment of personal care robots for older adults in terms of the innovativeness

Initially, the respondents rated the technology in terms of its innovativeness (Figure 2). Analysing Figure 2, it can be seen that the statement (14) met with the greatest acceptance of the respondents. Over $37 \%$ of respondents strongly believed that the use of robots to care for the older people was a breakthrough solution on the scale of Poland. In the case of I1 and I2, approximately $22 \%$ of respondents strongly agreed with these statements. On the other hand, about $30 \%$ strongly agreed with statements $\mathrm{I} 3$ and $\mathrm{I} 5$.

Then, the respondents assessed the technology in terms of marketing aspects (Figure 3). According to Figure 3, statements M7 and M4 were mostly accepted by the respondents. About $32 \%$ of respondents strongly agreed with the statement that the robot's appearance would have a significant impact on the scale of its use in everyday life and the use of robots to care for the aging population would be a source of additional benefits for their users. In the case of $\mathrm{M} 6$ and $\mathrm{M} 1$, less than $10 \%$ of respondents strongly agreed with these statements.

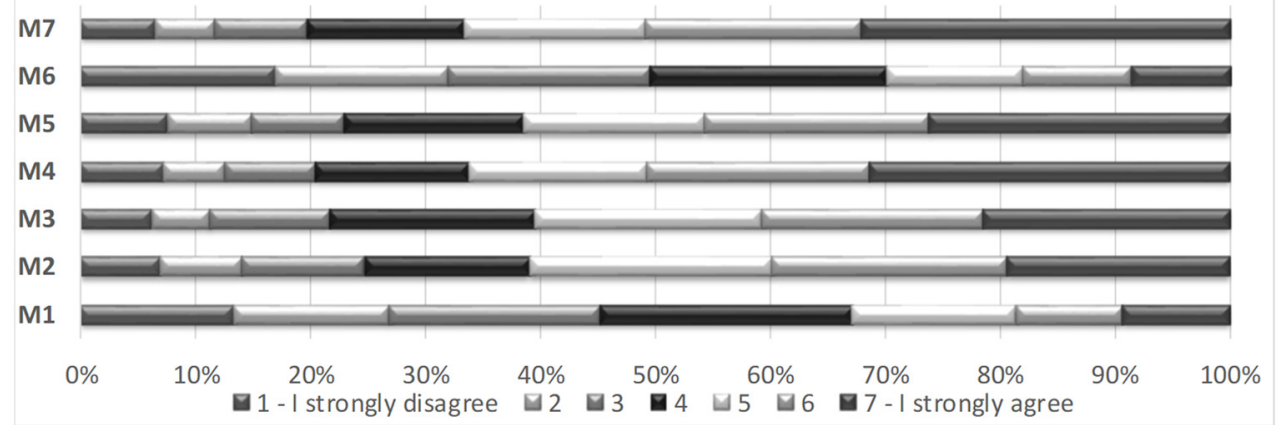

Fig. 3. Technology assessment of personal care robots for older adults in terms of marketing aspects

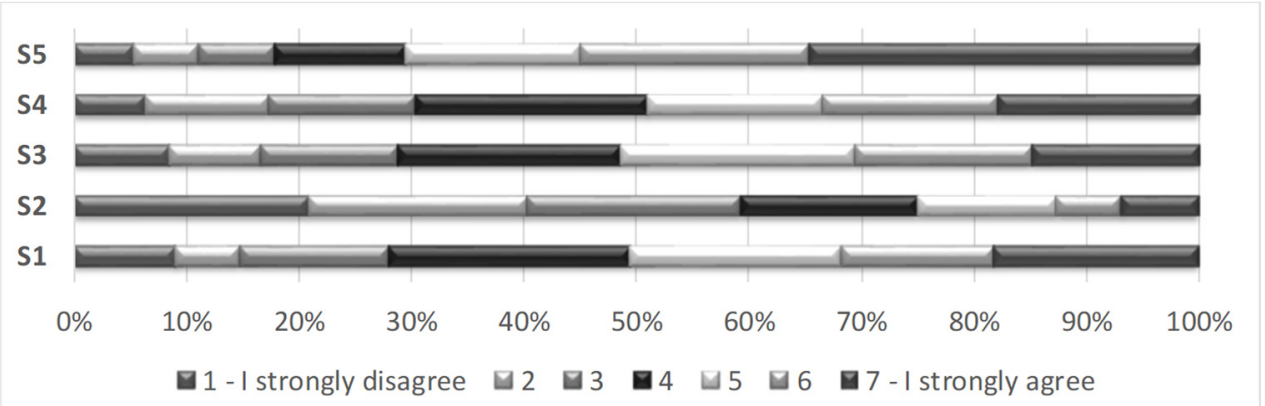

Fig. 4. Technology assessment of personal care robots for older adults in terms of socio-ethical aspects 
The respondents also made a technology assessment in terms of socio-ethical aspects (Figure 4). Analysing this figure, it can be seen that respondents strongly agreed with statement S5. About $35 \%$ of respondents believed that the widespread use of robots in the care of the older people could be the cause of moral dilemmas. About $18 \%$ of respondents strongly agreed with statements S1 and S4. Respondents said that the widespread use of robots in the care of the older people could be a source of social problems and the use of robots in the care of the aging population will bring measurable social benefits.

The responses of respondents regarding the usability of technology are depicted in Figure 5. According to the Figure, over $50 \%$ of respondents agreed or strongly agreed with the U3 statement. Therefore, half of the respondents believed that the use of robots would be of particular importance in the care of lonely people. In contrast, approximately $40 \%$ of respondents agreed or strongly agreed with statements U1 and U2. They believed that the widespread use of robots would improve the quality of services in the field of care for the aging population and improve the safety of older people.

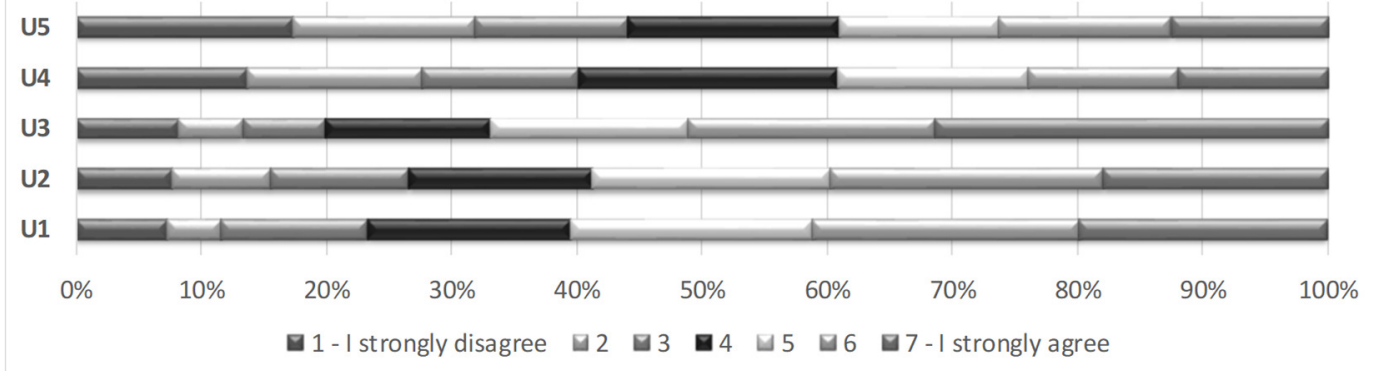

Fig. 5. Technology assessment of personal care robots for older adults in terms of the usefulness

Respondents also made a technology assessment regarding its functionality (Figure 6). According to Figure 6 , the respondents believed that the functionality of this technology was extremely important. Over $60 \%$ of respondents agreed or strongly agreed with statements $\mathrm{F} 1$, F2, F4 and F5. However, statements F2 and F5 were mostly accepted by the respondents. Over $65 \%$ of respondents strongly believed that a very important functionality of a robot would be the ability to call for help on behalf of an older person (F5). On the other hand, about $55 \%$ of respondents strongly agreed with the statement that an important functionality of a robot would be the ability to call for help on behalf of an older person (F2).

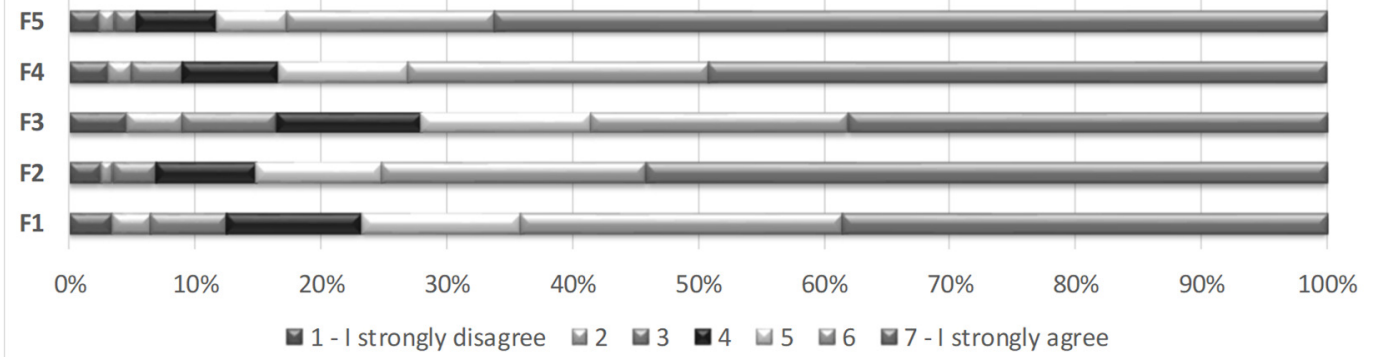

Fig. 6. Technology assessment of personal care robots for older adults in terms of the functionality

\section{GRAPHIC PRESENTATION OF THE CURRENT STATE OF TECHNOLOGY}

The last important research task related to the analysis and assessment of technology was a graphic presentation of the current state of technology. For this purpose, average scores of technologies of personal care robots for older adults in terms of the innovation criterion, 
marketing, socio-ethical aspects, usability and functionality were calculated based on individual data (Figure 7). According to Figure 7, the technology was mostly rated regarding its functionality and innovation. The average assessment of respondents' compliance with claims regarding the functionality of the technology was 5.82 (on a scale from 1 to 7 ). On the other hand, the average assessment of respondents' compliance with statements regarding innovation amounted to 4.87. In turn, the lowest score was given to technology in terms of socio-ethical aspects. The average assessment of respondents' compliance with statements regarding socio-ethical aspects was 3.69. Similarly, the respondents rated the technology regarding the marketing and usability aspects. The average of respondents' compliance assessments with those regarding the above-mentioned aspects was about 4.5.

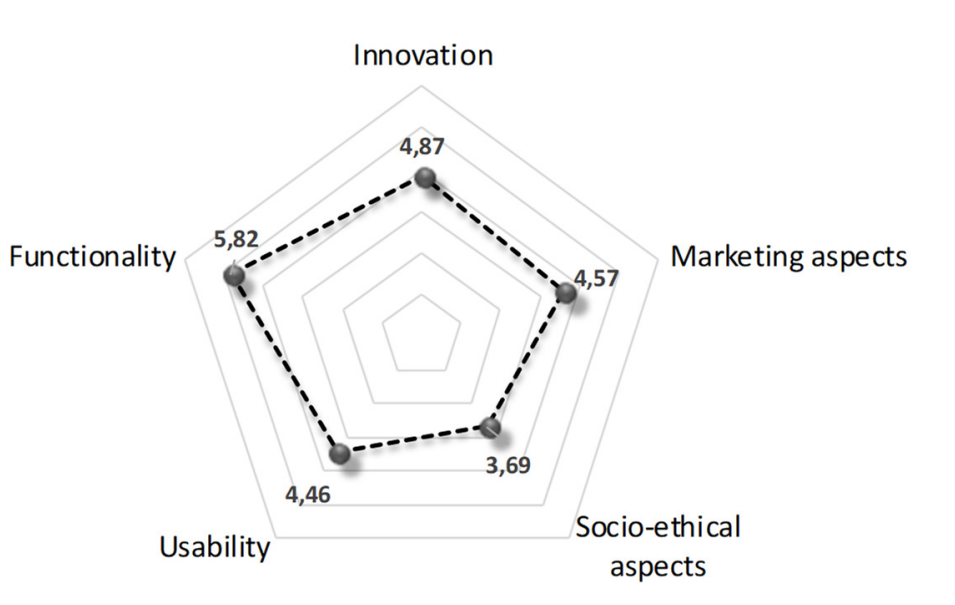

Fig. 7. Collective assessment of the technology of personal care robots for older adults in terms of the functionality

\section{CONCLUSION}

As part of the research, the aim was on the acquisition of new knowledge in the field of identifying criteria for the assessment of humanoid robot technology in the care for the aging population. Also, the evaluation of this technology has been carried out. Based on the study of the subject literature and the analysis of the results of primary and secondary research, the author identified a theoretical gap expressed in the absence of a coherent theory regarding the analysis of technologies improving the quality of life of older people. The empirical gap manifested by the lack of empirical research, addressing both to current and potential users of gerontechnology, in particular, humanoid robots in care for the older people. A methodical gap manifested in the form of a lack of methods and tools for the analysis and assessment of the technology. The research cycle carried out by the author filled in these cognitive gaps. The scientific activities presented under this article will expand the current state of knowledge in the field of humanoid robotic technology research in the care for the aging population, as well as original research work undertaken to acquire new knowledge in the analysis and assessment of technologies improving the quality of life of the ageing population.

The results of research tasks carried out under this article can be used as a knowledge base for the development of technology cards improving the quality of life of older people. In the cards, it is possible to collect and organise the most important information regarding the analysed gerontechnology aspects. They form a knowledge base presented in a synthetic and clear form on the subject of analysed technologies. They can be a kind of gerontechnology portfolio. Information prepared in this way may also facilitate further analysis or comparison of various technologies that improve the quality of life in Poland. Further scientific activities will include research on predicting the development of gerontechnology in Poland. 


\section{ACKNOWLEDGEMENTS}

The research was conducted within S/WZ/1/2017 project and financed from the funds of the Ministry of Science and Higher Education.

\section{REFERENCES}

Bronswijk, J.E.M.H., Bouma, H., Fozard, J.L., Kearns, W.D., Davison, G.C. (2009). Defining Gerontechnology for R\&D Purposes. Rehabilitation and Mental Health Counseling Faculty Publications, 31, pp. 1-10.

Cagnin, C., Keenan, M., Johnston, R., Scapolo, F., Barré, R. (2008). Future-oriented technology analysis. Strategic intelligence for an innovative economy. Berlin: Springer.

Ejdys, J., Gedvilaite, D. (2017). Learning orientation in nursing homes in Poland. Engineering Management in Production and Services, 9(3), pp. 51-63.

Ejdys, J. (2015). Innovativeness of residential care services in Poland in the context of strategic orientation. Procedia - Social and Behavioral Sciences, 213, pp. 746-752.

Görer, B., Salah, A.A., Akın, H.I., (2017). An autonomous robotic exercise tutor for elderly people, Auton Robot, 41 , pp. 657-678

Graafmans, J., Taipale, V., Charness, N. (1998.). Gerontechnology. A sustainable investment in the future. Amsterdam: IOS Press.

Haegeman, H., Marinelli, E., Scapolo, F., Ricci, A., Sokolov, A. (2013). Quantitative and qualitative approaches in Future-oriented Technology Analysis (FTA): from combination to integration? Technol Forecast Soc Change, 80(2), pp. 386-397.

Halicka, K. (2016). Innovative classification of methods of the future-oriented technology analysis. Technological and Economic Development of Economy, 22(4), pp. 574-597.

Mostaghel, R., Oghazi, P. (2017). Elderly and technology tools: a fuzzyset qualitative comparative analysis. Qual Quant, 51, pp. 1969-1982.

Nazarko, J., Ejdys, J., Halicka, K., Magruk, M., Nazarko, Ł., Skorek, A. (2017). Factor Analysis as a Tool Supporting STEEPVL Approach to the Identification of Driving Forces of Technological Innovation. Procedia Engineering, 182, pp. 491-496.

Nazarko, Ł. (2017). Future-Oriented Technology Assessment. Procedia Engineering, 182, pp. 504-509.

Radziszewski, P., Nazarko, J., Vilutiene, T., Dębkowska, K., Ejdys, J., Gudanowska, A., Halicka, K., Kilon, J., Kononiuk, A., Kowalski, K. J., Król, J B., Nazarko, Ł., Sarnowski, M. (2016). Future trends in road pavement technologies development in the context of environmental protection. The Baltic Journal of Road and Bridge Engineering, 11(2), pp. 160-168. 